\title{
Gender and the risk of stroke in atrial fibrillation: impact of old and new anticoagulation regimens
}

\author{
Stavros Z. Apostolakis $\cdot$ Stavros V. Konstantinides
}

Published online: 16 February 2013

(C) Springer-Verlag Berlin Heidelberg 2013

\begin{abstract}
Atrial fibrillation (AF) is the most common sustained arrhythmia. Thromboembolic events related to AF result in significant morbidity and mortality. An individual's risk of thromboembolism in the setting of AF varies significantly based on clinical and demographic characteristics. The risk of stroke appears to be greater among women with AF than men. Warfarin provides sufficient protection against stroke, but does not eliminate gender differences in stroke rates. New oral anticoagulants demonstrated similar or superior efficacy compared to warfarin; however rates of stroke in women on new agents remain higher than those observed in men. In the present article, we review the reported gender-related differences in stroke rates in both anticoagulated and nonanticoagulated patient populations. We also focus on differences in stroke and bleeding rates among men and women treated with new oral anticoagulants. Finally, we explore potential sex-based differences in the efficacy and safety of new oral anticoagulants as reflected in the results of the landmark phase III trials.
\end{abstract}

\footnotetext{
S. V. Konstantinides, MD, PhD, FESC ( $\square)$

Centre for Thrombosis and Hemostasis, Johannes Gutenberg

University Medical Centre, Langenbeckstraße 1, Geb. 403,

55131 Mainz, Germany

e-mail: stavros.konstantinides@unimedizin-mainz.de
}

S. Z. Apostolakis · S. V. Konstantinides, MD, PhD, FESC

Department of Cardiology, University General Hospital,

Democritus University of Thrace, Alexandroupolis, Greece

\section{S. Z. Apostolakis}

Haemostasis, Thrombosis and Vascular Biology Unit, University of Birmingham Centre for Cardiovascular Science, City Hospital, Birmingham, UK
Keywords Atrial fibrillation - Stroke · Embolism · Gender · Women · Anticoagulation · Vitamin K antagonists $\cdot$ Dabigatran $\cdot$ Rivaroxaban $\cdot$ Apixaban

\section{Introduction}

Atrial fibrillation (AF) is the most common sustained supraventricular arrhythmia [1-3]. The estimated overall prevalence of $\mathrm{AF}$ is $0.9 \%$ in the North American population, steadily increasing with age [1, 3, 4]; a similar prevalence has been reported in most regions of the Western Europe [5]. Stroke, as a complication of AF, is an important cause of morbidity and mortality. In the AF population as a whole, the absolute risk of stroke averages about $5 \%$ per year and is thus approximately 5-6 times higher than the risk among age-matched individuals who are in sinus rhythm. On the other hand, the individual risk of stroke varies widely among patients with AF depending on demographic and clinical features [6-8].

The annual incidence of AF has been reported to be higher in men than in women across all age groups. This gender-related difference was initially observed by the Framingham investigators $[1,2]$ and subsequently supported by the findings of prospective registries [5]. Similarly, the overall prevalence of $\mathrm{AF}$ has been reported to be approximately $20-40 \%$ higher in men than in women $[4,5]$. Interestingly however, and despite the above differences apparently favoring women, the lifetime risk of developing AF seems to be similar in both sexes, probably due to the greater life expectancy of women as opposed to men [5].

Gender also seems to have an impact on the risk of systemic thromboembolism in AF patients. Rates of stroke in women with $\mathrm{AF}$ were reported higher compared to those in men. This observation has been made both by prospective 
registries and by randomized trials involving anticoagulated as well as nonanticoagulated populations $[7,9,10]$. However, it should be noted that not all studies were able to confirm such a relationship $[6,8]$.

In the present article, we critically review the available evidence on gender-related differences with regard to (1) the baseline risk of thromboembolism in AF; (2) the efficacy and bleeding risks of anticoagulation with Vitamin $\mathrm{K}$ antagonists (VKA); and (3) the stroke and bleeding rates of patients treated with new oral anticoagulants (OACs) in the recently published megatrials.

\section{Gender and the baseline risk of thromboembolism}

The Framingham investigators have reported female sex to be an independent risk factor for stroke among patients with AF [11]. Moreover, in 1994, the Atrial Fibrillation Investigators (AFI) published the results of a systemic review involving the control arms of five randomised trials that compared VKAs against antiplatelet therapy or placebo in stroke prevention in the setting of AF. The authors reported slightly higher rate of stroke in women compared to men; this difference, however, did not reach statistical significance (relative risk (RR), 1.2; $95 \%$ confidence interval (CI), 0.8-1.8; $P=0.18$ ) [6]. In 1999, the Stroke Prevention in Atrial Fibrillation (SPAF) investigators reported the results of a post hoc analysis involving 2,012 participants who had been given aspirin, alone or in combination with low (inefficacious) doses of warfarin, in the SPAF I-III trials [7]. The authors concluded that female sex multiplied the risk of stroke 1.6-fold in the population of the three studies.

Besides the (post hoc) analysis of trial data, prospective registries also have reported on the association between female sex and the risk of stroke. The Anticoagulation and Risk Factors in Atrial Fibrillation (ATRIA) study cohort included 5,795 women and 7,764 men [9]. Rates of thromboembolism among male and female patients not taking anticoagulants were assessed while controlling for other known risk factors of stroke. A higher annual incidence of thromboembolism was reported in women (RR, 1.6; $95 \%$ CI, 1.3-1.9). Most recently, Friberg et al. [10] evaluated the risk of stroke in men and women in the largest-ever registry that has addressed this issue. The registry population included 100,802 patients with AF who were not taking OAC. The study showed a higher risk of stroke in women, with an adjusted hazards ratio of 1.18 (95\% CI, 1.12-1.24) compared with men [10].

In summary, post hoc analysis of early clinical trials provided partly conflicting data on the differences in stroke rates between men and women. On the other hand, large sets of data from more recent cohorts could confirm female gender as an independent predictor of stroke in the setting of AF. Female gender appears to confer a relative stroke risk ranging from 1.2 to 1.9 . This may be partly explained by the important fact that risk factor profiles differ significantly between women and men with AF. For example, men develop coronary disease more frequently, while women with $\mathrm{AF}$ tend to be older and have more comorbidities. In the SPORTIF trials, for example, more women were hypertensive and had higher overall systolic blood pressure values than men [12]. In fact, risk factor control has been reported to be poorer in women compared to men; this includes higher blood pressure and cholesterol levels [13-15]. Overall, cardiovascular risk is still underestimated in women and modifiable cardiovascular risk factors continue to be managed less aggressively in women compared to men [13-16]. This seems to include the underuse of anticoagulants and the poorer anticoagulation control in women with AF compared to men. Finally, it appears that certain thromboembolic risk factors such as diabetes and metabolic syndrome may have different effects on women compared to men $[17,18]$.

\section{Vitamin $\mathrm{K}$ antagonists and the risk of stroke in women with atrial fibrillation}

It is unclear whether treatment with VKA is capable of preventing stroke equally in both sexes. In fact, few studies have examined gender-related differences in the response to anticoagulation therapy. Five randomised primary prevention trials have shown that, in nonvalvular $\mathrm{AF}$, warfarin reduces the annual risk of stroke from an average of $4.5 \%$ (in nonanticoagulated individuals) to $1.4 \%$, with a significant but "acceptable" increase in major bleeding rates. In total, these trials included 1,225 patients in the warfarin arm and 1,238 patients in the respective control arms [19-23]. The proportion of women in the recruited population ranged from 0 to $47 \%$. In total, $306(25 \%)$ and 334 (27\%) women were randomized in the warfarin and control arms respectively. Thus, considering the epidemiological data on the prevalence of $\mathrm{AF}$ in women vs. men, the female sex was clearly underrepresented in the primary prevention trials. As already mentioned, a metaanalysis of these five trials reported that women assigned to the control group had a slightly (albeit statistically nonsignificant) higher risk of stroke than men [6]. Interestingly, and perhaps due to their higher baseline risk of stroke, women with AF seemed to benefit more from VKA treatment compared to men: in women, warfarin decreased the risk of stroke by $84 \%$ (95\% CI, 55-95\%; $P<0.001)$, compared with $60 \%(95 \% \mathrm{CI}$, $35-76 \% ; P<0.001)$ in men [6].

Moving from primary to secondary prevention, the European Atrial Fibrillation Trial (EAFT) investigators randomised 1,007 patients with a recent TIA or minor ischemic 
stroke to open anticoagulation or double-blind treatment with either aspirin or placebo [24]. The authors concluded that, in patients with chronic nonvalvular AF and a history of stroke or TIA, the annual risk of stroke is reduced from 12 to $4 \%$ with warfarin. The EAFT trial recruited an almost balanced population with respect to gender, as 45 and $42 \%$ of the recruited patients in the warfarin and control arms respectively were women. Nevertheless, the low absolute number of participants in the warfarin arm (225 in total; 101 women) did not permit any conclusions on the possible interaction between sex and the benefit derived from anticoagulation in AF. The landmark Atrial Fibrillation Follow-up Investigation of Rhythm Management (AFFIRM) included 4,060 patients, $39.3 \%$ of whom were women. Approximately $13 \%$ of the AFFIRM population had a history of stroke or TIA, and oral anticoagulation was prescribed in all patients randomized in the rate control arm. Moreover, oral anticoagulation was encouraged in all patients in the rhythm control arm throughout the study period [25]. Female sex was one of the five baseline factors that were independently associated with the risk of stroke in the followup period. In fact, female sex conferred a $66 \%$ higher risk of stroke in the AFFIRM population [25].

Similar to the results of randomised trials are the observations of large prospective registries. The ATRIA investigators reported that, despite a similar distribution of INR values, the reduction in the rates of thromboembolism under warfarin was larger in women than in men [9]. More specifically, anticoagulation with warfarin reduced annual rates of thromboembolism from 3.5 to $1.5 \%$ (a $57 \%$ relative risk reduction) in women, as opposed to a reduction from 1.8 to $1.2 \%$ (a $33 \%$ relative risk reduction) in men ( $P=0.001$ for the interaction between sex and benefit from warfarin) [9]. These observations suggest that anticoagulation with VKA does not eliminate differences in stroke rates among men and women. In further support of this latter notion, a report from the Euro Heart Survey showed that women were still at higher risk of stroke than men, despite the lack of difference in VKA prescription rates [26].

Very few studies were specifically designed to assess the impact of gender on the outcome of anticoagulated patients. Poli et al. [27] prospectively assessed the impact of gender on the risk for stroke in $780 \mathrm{AF}$ patients. The authors concluded that women had a twofold higher risk of stroke compared to men. Moreover, strokes in women were more severe and these differences were observed despite a similar quality of anticoagulation. Higher event rates were also observed in women in the warfarin arms of all the trials that assessed new oral anticoagulants.

In summary, it seems that VKA are effective for stroke prevention in women, possibly more so than in men, but this does not suffice to eliminate sex differences in stroke rates in AF patients. In all studies that assessed the risk of stroke in anticoagulated populations, the event rates were higher in women. In several studies, these differences reached statistical significance.

\section{Vitamin $\mathrm{K}$ antagonists and risk of bleeding in women with atrial fibrillation}

The available data on differences in bleeding risk among sexes are scarce and contradictory. In the ATRIA study, women had similar rates of major haemorrhage compared with men but were less likely to develop intracranial haemorrhage on warfarin therapy [9]. Similarly, in the AFFIRM study, no differences were observed in the rates of bleedings between the sexes [28]. On the other hand, the Euro Heart Survey investigators reported significantly higher major bleeding rates in women compared to men (2.2 vs. $1.3 \%$; $P=0.028$ ) [20]. The Canadian Registry of Atrial Fibrillation (CARAF) also reported that women on warfarin had a more than threefold higher risk to experience a major bleeding event than men [29]. Importantly however, in the latter registry major bleedings in women were strongly driven by poorly controlled INR as reflected by mean INR of $4.02 \pm 2.96$ in the women that experienced major bleeding. Poorer anticoagulation control in women compared to men has been reported by the Veterans Affairs Study to Improve Anticoagulation (VARIA) investigators [30]. In further support of the view that poor anticoagulation control is the reason of higher bleeding rates in women, Poli et al. [27] prospectively analyzed AF patients followed in an outpatient anticoagulation clinic with careful INR management. The investigators concluded that there were no differences in major bleeding rates between women and men (1.3 vs. $1.4 \% ; P=1.0)$.

In conclusion, there is no clear evidence of a higher susceptibility of women to VKA-related bleeding when the quality of oral anticoagulation is ensured. When higher bleeding rates in women are observed, they are likely related to poorer anticoagulation control.

\section{New oral anticoagulants and outcomes in women with atrial fibrillation}

Five recent phase III trials tested new oral anticoagulants against warfarin in stroke prevention in patients with $\mathrm{AF}$ [31-35] (Table 1). In total, 58,337 patients were randomized to new treatments or warfarin. Women represented $35.8 \%$ (range, 30-39.7\%) of the population, yielding a male-tofemale ratio of 1.8:1. Thus, given the prevalence of AF in epidemiological studies, women were slightly underrepresented in the new OAC trials (albeit less so than in the ear- 
Table 1 Summary of landmark clinical trials on new oral anticoagulants, including numbers of female participants

\begin{tabular}{|c|c|c|c|c|}
\hline & SPORTIF III\&V $[31,32]$ & RE-LY [33] & ROCKET-AF [34] & ARISTOTLE [35] \\
\hline Trial design & $\begin{array}{l}\text { Open-label, } \\
\text { non-inferiority }\end{array}$ & $\begin{array}{l}\text { Single-blind, } \\
\text { non-inferiority }\end{array}$ & $\begin{array}{l}\text { Double-blind, double-dummy, } \\
\text { non-inferiority }\end{array}$ & $\begin{array}{l}\text { Double-blind, double-dummy, } \\
\text { non-inferiority }\end{array}$ \\
\hline Drug & Ximelagatran & Dabigatran & Rivaroxaban & Apixaban \\
\hline Dose & $36 \mathrm{mg}$ twice daily & $\begin{array}{l}110 \mathrm{mg} \text { or } 150 \mathrm{mg} \text { twice } \\
\text { daily }\end{array}$ & $\begin{array}{l}20 \mathrm{mg} \text { once daily } \\
(15 \mathrm{mg} \text { daily for patients with } \\
\text { creatinine clearance } 30-49 \mathrm{~mL} / \\
\text { min) }\end{array}$ & $\begin{array}{l}5 \mathrm{mg} \text { twice daily } \\
(2.5 \mathrm{mg} \text { twice daily for patients } \\
\text { with two or more of the fol- } \\
\text { lowing criteria: age } \geq 80 \text { years, } \\
\text { body weight } \leq 60 \mathrm{~kg} \text { or serum } \\
\text { creatinine } \geq 1.5 \mathrm{mg} / \mathrm{dL})\end{array}$ \\
\hline Comparator & Warfarin & Warfarin & Warfarin & Warfarin \\
\hline Participants (n) & 7,329 & 18,113 & 14,264 & 18,201 \\
\hline Women & $2,257(30.7)$ & $6,599(36.4)$ & $5,663(39.7)$ & $6,416(35.3)$ \\
\hline Age $^{\text {a }(\text { years })}$ & 71 & 71.5 & 73 & 70 \\
\hline $\begin{array}{l}\text { Previous } \\
\text { stroke/TIA (\%) }\end{array}$ & 25.5 & 20 & 55 & 20 \\
\hline $\begin{array}{l}\mathrm{CHADS}_{2} \\
\text { (mean) }\end{array}$ & Not reported & 2.1 & 3.5 & 2.1 \\
\hline Mean follow up & 17.4 months & 2 years & 707 days & 1.8 years \\
\hline TTR $(\%)$ & 67 & 64 & 55 & 62 \\
\hline
\end{tabular}

ARISTOTLE Apixaban for Reduction of Stroke and Other Thromboembolism Events in Atrial Fibrillation, RE-LY Randomised Evaluation of Long-term Anticoagulant treatment, ROCKET-AF Rivaroxaban Once daily oral direct Factor Xa inhibition Compared with vitamin K antagonism for prevention of stroke and Embolism Trial in Atrial Fibrillation, SPORTIF Stroke Prevention using an Oral Thrombin Inhibitor in Atrial Fibrillation, TIA transient ischaemic attack, TTR time in therapeutic range

${ }^{\mathrm{a}}$ Mean age for RE-LY and SPORTIF, median age for ARISTOTLE and ROCKET-AF

Table 2 Event rates in men and women in phase III trials on new oral anticoagulants

\begin{tabular}{|c|c|c|c|c|c|c|}
\hline & & \multicolumn{2}{|c|}{ Event rates } & \multirow[t]{2}{*}{$\begin{array}{l}\text { Relative risk } \\
\text { women vs. men }\end{array}$} & \multicolumn{2}{|c|}{$\begin{array}{l}\text { Relative risk reduction warfarin vs } \\
\text { new OAC }\end{array}$} \\
\hline & & Women & Men & & Women & Men \\
\hline \multirow[t]{2}{*}{ SPORTIF [12] } & Warfarin & 1.98 & 1.51 & 1.31 & -0.1 & 0.09 \\
\hline & Ximeligatran & 2.17 & 1.38 & 1.57 & & \\
\hline \multirow[t]{3}{*}{ RE-LY [33] } & Warfarin & 2.03 & 1.49 & 1.36 & 0.08 & 0.09 \\
\hline & Dabigatran 110 & 1.86 & 1.35 & 1.38 & & \\
\hline & Dabigatran 150 & 1.14 & 1.10 & 1.04 & 0.44 & 0.26 \\
\hline \multirow[t]{2}{*}{ ROCKET-AF [34] } & Warfarin & 5.07 & 3.83 & 1.32 & 0.11 & 0.13 \\
\hline & Rivaroxaban & 4.5 & 3.34 & 1.35 & & \\
\hline \multirow[t]{2}{*}{ ARISTOTLE [35] } & Warfarin & 1.8 & 1.5 & 1.2 & 0.22 & 0.2 \\
\hline & Apixaban & 1.4 & 1.2 & 1.17 & & \\
\hline
\end{tabular}

ARISTOTLE Apixaban for Reduction of Stroke and Other Thromboembolism Events in Atrial Fibrillation, RE-LY Randomised Evaluation of Long-term Anticoagulant treatment, ROCKET-AF Rivaroxaban Once daily oral direct Factor Xa inhibition Compared with vitamin K antagonism for prevention of stroke and Embolism Trial in Atrial Fibrillation, SPORTIF Stroke Prevention using an Oral Thrombin Inhibitor in Atrial Fibrillation, $O A C$ oral anticoagulant

lier VKA trials discussed above). The event rates observed in men and women are summarized in Table 2.

\section{Ximelagatran}

Ximelagatran was the first oral direct thrombin inhibitor reaching phase III development as an anticoagulant for prevention of AF-related thromboembolism [31, 32]. Although the drug was withdrawn from the market as early as 2006 due to hepatotoxicity, the results of the ximelagatran trials deserve to be presented and briefly discussed. The Stroke Prevention using an ORal Thrombin Inhibitor in atrial Fibrillation (SPORTIF) program compared ximelagatran with warfarin for stroke prevention in AF. In total, 7,329 patients were recruited in SPORTIF III and V trials; approximately $30 \%$ of them were women $[31,32]$. Despite the underrepresentation of the female sex, the SPORTIF trials 
provided, until 2009, the largest available clinical database of anticoagulated women with AF. Moreover, the SPORTIF III and V trials remain until now the only studies that provided information about gender-related differences in rates of ischaemic events among anticoagulated patients. Gomberg-Maitland et al. [12] reported that, more women than men developed primary events (stroke or systemic embolism), with 72 women experiencing events during 3,465 patient-years vs. 112 men during 7,759 patient-years (annual rate per 100 patients, 2.8 vs. $1.44 ; P=0.016$ ). This difference was driven by the ximelagatran group ( 2.17 vs. 1.38 , $P=0.03$ ), while there was no significant difference between the sexes in the primary event rates in the warfarin group. Moreover, women had higher rates of combined major and minor bleedings ( 41.3 vs. $33.9 \%$ in men; $P<0.001$ ).

Dabigatran etexilate is a direct thrombin inhibitor with a rapid onset of action (1-2 h), short half-life (12-17 h) and predominant renal excretion [37]. The Randomized Evaluation of Long-Term Anticoagulation Therapy (RE-LY) trial was a randomized, open-label, multicenter, (primarily) noninferiority study. RE-LY compared the efficacy and safety of two fixed doses of dabigatran $(150 \mathrm{mg}$ twice daily and $110 \mathrm{mg}$ twice daily) with INR-adjusted-dose warfarin [33]. The study recruited 18,113 AF patients with an average age of 71 years. The primary endpoint was the incidence of stroke (including hemorrhagic strokes) and systemic embolism during a 2-year follow-up period (median). The study demonstrated that treatment with the higher $(150 \mathrm{mg}$ twice daily) dose was superior to warfarin in reducing stroke and systemic embolism (relative risk, $0.66 ; P<0.001$ ), with an overall major bleeding risk similar to that of warfarin. The lower (110 mg bid) dose resulted in a similar risk for stroke as warfarin (noninferiority), but with $20 \%$ reduction in the rate of major bleeding events $(3.36 \%$ per year in the warfarin group vs. $2.71 \%$ per year with dabigatran, $P=0.003$ ). Importantly, the rates of hemorrhagic stroke, which were $0.38 \%$ per year in the warfarin group, were reduced to $0.12 \%$ per year with lower-dose dabigatran $110 \mathrm{mg}(P<0.001)$ and to $0.10 \%$ per year with higher-dose dabigatran $(P<0.001)$. Mortality benefits did not reach statistical significance for either dose of dabigatran compared to warfarin [33].

In total, RE-LY recruited 6,599 (36.4\%) women: 2,150 (35.7\%), 2,236 (36.8\%), and 2,213 (36.7\%) in the dabigatran $110 \mathrm{mg}$, dabigatran $150 \mathrm{mg}$, and warfarin arms, respectively. The annual rates of stroke in the warfarin arm were 2.03 and 1.49 per 100 patient-years in women and men respectively. Similar higher rates of stroke were observed in women compared to men in the dabigatran arms. The benefit of dabigatran $150 \mathrm{mg}$ over warfarin for the prevention of stroke was independent of gender. Nevertheless, women appeared to have a greater relative risk reduction under dabigatran than men (Table 2). In a recent subanalysis of the
RE-LY trial, no significant interaction between sex and the risk of major bleeding was reported [36]. Similarly, rates of intracranial hemorrhage did not differ among sexes in the RE-LY population [37].

\section{Rivaroxaban}

Rivaroxaban is an oral direct factor Xa inhibitor [38]. After oral administration, it achieves peak concentration in plasma within $3 \mathrm{~h}$. It has a half-life of $6-10 \mathrm{~h}$ and two-thirds of rivaroxaban is excreted by the kidneys (Table 1). The Rivaroxaban Once Daily Oral Direct Factor Xa Inhibition Compared with Vitamin K Antagonism for Prevention of Stroke and Embolism Trial in Atrial Fibrillation (ROCKETAF) trial assessed the efficacy of rivaroxaban in preventing AF-related thromboembolism. ROCKET-AF was a doubleblind, randomized trial of 14,264 patients comparing rivaroxaban (20 mg once daily) to adjusted dose warfarin [28]. The mean age was 73 years, and $87 \%$ of participants had a $\mathrm{CHADS}_{2}$ score $\geq 3$ (mean score, 3.47). In the per-protocol, as-treated analysis, rivaroxaban was superior to warfarin, but superiority was not confirmed in the intention-to-treat analysis $(P=0.12)$. The rates of major bleedings were similar, but fatal bleeding was less frequent with rivaroxaban. Intracranial bleeding rates were also significantly less frequent with rivaroxaban [34].

In total, $39.7 \%$ of ROCKET-AF population was of women. The study recruited 2,831 and 2,832 women in the rivaroxaban and warfarin arm, respectively. Event rates in the rivaroxaban arm were 4.06 and 3.6 per 100 patient years for women and men, respectively. In the warfarin arm, event rates were 5.07 per 100 patient years in women compared to 3.83 in men. As in RE-LY, there was no interaction between sex and the benefit obtained from rivaroxaban therapy. Interestingly, in ROCKET-AF, the recruited population was more representative of the "real-world" prevalence of AF in women vs. men. This is most likely a result of the higherrisk population - as reflected by $\mathrm{CHADS}_{2}$ score - that the study was designed to recruit. Since women with AF tend to be older and have more comorbidities than men, they are expected to comprise a larger part of a selected-high risk population. With respect to the safety endpoint of major and nonmajor clinically relevant bleedings, a statistically significant interaction was reported among sex and treatment arms. Bleeding events were higher in men in the rivaroxaban vs. warfarin group (22.6 vs. $20.89 \%$; HR, 1.12; $95 \%$ CI, $1.02-1.22 ; P=0.004)$. In contrast, the annual rate of bleeding events in women tended to be higher in the warfarin than in the rivaroxaban group (19.5 vs. $17.9 \%)$, although this latter difference was not statistically significant [34]. 


\section{Apixaban}

Apixaban is an oral direct FXa inhibitor. It has half-life of $8-15$ hours and $25 \%$ renal excretion [36]. The Apixaban for Reduction in Stroke and Other Thromboembolic Events in Atrial Fibrillation (ARISTOTLE) trial compared apixaban with warfarin in 18,201 patients with $\mathrm{AF}$ and $\geq 1$ additional risk factor for stroke [35]. In ARISTOTLE, apixaban reduced the risk of stroke or systemic embolism by $21 \%$ compared with warfarin (1.27 vs. $1.60 \%$ per year). The reduction was significant and supported the superiority of apixaban over warfarin for the primary outcome of stroke and systemic embolism ( $P=0.01$ for superiority). Apixaban also reduced all-cause mortality by $11 \%(P=0.047)$ and major bleeding by $31 \%(P<0.001)$ compared with warfarin [35].

Overall, ARISTOTLE recruited 6,416 (35.3\%) women: $3,234(35.5 \%)$ and $3,182(35.0 \%)$ in the apixaban and warfarin arms, respectively. Event rates in the apixaban arm were 1.4 per 100 patient years in women and 1.2 per 100 patient years in men. Similarly, in the warfarin arm, women had higher event rates compared to men (1.8 vs. 1.5 per 100 patient-years). However, as in the RE-LY trial, there was not statistically significant interaction between gender and the benefit from apixaban therapy. Bleeding rates in the ARISTOTLE trial did not differ among men and women in the apixaban or in the warfarin arm. Interestingly, as in the ROCKET-AF study women had arithmetically higher bleeding rates when on warfarin and lower bleeding rates when on the factor Xa inhibitor compared to men. There was no statistically significant interaction among sex and safety endpoint rates among control and experimental arms [35].

\section{Conclusions}

Female gender is an independent risk factor for AF-related thromboembolism. This appears to be true for both anticoagulated and nonanticoagulated patients. Vitamin K antagonists are effective for stroke prevention in women, possibly more so than in men, but this does not appear to suffice to eliminate the sex-related differences leading to higher stroke rates in women with AF.

In general, women have not been adequately represented in early studies assessing the impact of anticoagulation on stroke prevention in the setting of AF. This is also true, at least in part, for the recent phase III studies on new oral anticoagulants.

All landmark trials demonstrated that new anticoagulants are at least as effective as warfarin in preventing thromboembolism in patients in AF. This effect was irrespective of clinical and demographic factors, including gender. Nevertheless, and in accordance with what was stated above, women exhibited higher absolute event rates than men in all five trials, both in the experimental and in the control (VKA) arm.

Limited information is available on the risk of OACrelated bleeding in women. There is no data however to support higher susceptibility of women to anticoagulationrelated bleeding, regardless of the use of VKAs or new oral agents.

In conclusion, female gender confers an increased risk of stroke in atrial fibrillation. This fact underlines the urgent need for improvement in the assessment and management of cardiovascular risk in women, including the implementation of state-of-the-art anticoagulation strategies.

Acknowledgments This article is part of a supplement sponsored by Lilly Deutschland GmbH and Daiichi Sankyo Deutschland GmbH.

\section{Conflict of interest None.}

\section{References}

1. Wolf PA, Benjamin EJ, Belanger AJ, Kannel WB, Levy D, D'Agostino RB (1996) Secular trends in the prevalence of atrial fibrillation: the Framingham study. Am Heart J 131:790-795

2. Benjamin EJ, Levy D, Vaziri SM, D’Agostino RB, Belanger AJ, Wolf PA (1994) Independent risk factors for atrial fibrillation in a population-based cohort: the Framingham heart study. J Am Med Assoc 271:840-844

3. Feinberg WM, Blackshear JL, Laupacis A, Kronmal R, Hart RG (1995) Prevalence, age distribution and gender of patients with atrial fibrillation. Arch Intern Med 155:469-473

4. Go AS, Hylek EM, Phillips KA, Chang Y, Henault LE, Selby JV, Singer DE (2001) Prevalence of diagnosed atrial fibrillation in adults: national implications for rhythm management and stroke prevention: the Anticoagulation and Risk Factors in Atrial Fibrillation (ATRIA) study. J Am Med Assoc 285:2370-2375

5. Heeringa J, Van Der Kuip DA, Hofman A, Kors JA, van Herpen G, Stricker BH, Stijnen T, Lip GY, Witteman JC (2006) Prevalence, incidence and lifetime risk of atrial fibrillation: the Rotterdam study. Eur Heart J 27:949-953

6. Atrial Fibrillation Investigators (1994) Risk factors for stroke and efficacy of antithrombotic therapy in atrial fibrillation: analysis of pooled data from five randomized controlled trials. Arch Intern Med 154:1449-1457

7. Hart RG, Pearce LA, McBride R, Rothbart RM, Asinger RW (1999) Factors associated with ischemic stroke during aspirin therapy in atrial fibrillation: analysis of 2,012 participants in the SPAF I-III clinical trials. The Stroke Prevention in Atrial Fibrillation (SPAF) investigators. Stroke 30:1223-1229

8. Hughes M, Lip GY; Guideline Development Group, National Clinical Guideline for Management of Atrial Fibrillation in Primary and Secondary Care, National Institute for Health and Clinical Excellence (2008) Stroke and thromboembolism in atrial fibrillation: a systematic review of stroke risk factors, risk stratification schema and cost effectiveness data. Thromb Haemost 99:295-304 
9. Fang MC, Singer DE, Chang Y, Hylek EM, Henault LE, Jensvold NG, Go AS (2005) Gender differences in the risk of ischemic stroke and peripheral embolism in atrial fibrillation: the Anticoagulation and Risk Factors in Atrial Fibrillation (ATRIA) study. Circulation 112:1687-1691

10. Friberg L, Benson L, Rosenqvist M, Lip GY (2012) Assessment of female sex as a risk factor in atrial fibrillation in Sweden: nationwide retrospective cohort study. Br Med J 344:e3522

11. Wang TJ, Massaro JM, Levy D, Vasan RS, Wolf PA, D'Agostino RB, Larson MG, Kannel WB, Benjamin EJ (2003) A risk score for predicting stroke or death in individuals with new-onset atrial fibrillation in the community: the Framingham Heart Study. J Am Med Assoc 290:1049-1056

12. Gomberg-Maitland M, Wenger NK, Feyzi J, Lengyel M, Volgman AS, Petersen P, Frison L, Halperin JL (2006) Anticoagulation in women with non-valvular atrial fibrillation in the stroke prevention using an oral thrombin inhibitor (SPORTIF) trials. Eur Heart J 27:1947-1953

13. Towfighi A, Saver JL, Engelhardt R, Ovbiagele B (2006) A midlife stroke surge among women in the United States. Neurology 69:1898-1904

14. Mosca L, Merz NB, Blumenthal RS, Cziraky MJ, Fabunmi RP, Sarawate C, Watson KE, Willey VJ, Stanek EJ (2005) Opportunity for intervention to achieve American Heart Association guidelines for optimal lipid levels in high-risk women in a managed care setting. Circulation 111:488-493

15. Mosca L, Linfante AH, Benjamin EJ, Berra K, Hayes SN, Walsh BW, Fabunmi RP, Kwan J, Mills T, Simpson SL (2005) National study of physician awareness and adherence to cardiovascular disease prevention guidelines. Circulation 111:499-510

16. Lip GY, Frison L, Grind M (2007) Effect of hypertension on anticoagulated patients with atrial fibrillation. Eur Heart J 28:752-759

17. Almdal T, Scharling H, Jensen JS, Vestergaard H (2004) The independent effect of type 2 diabetes mellitus on ischemic heart disease, stroke, and death: a population-based study of 13,000 men and women with 20 years of follow-up. Arch Intern Med 164:1422-1426

18. Ford ES, Giles WH, Dietz WH (2002) Prevalence of the metabolic syndrome among US adults: findings from the third national health and nutrition examination survey. J Am Med Assoc 287:356-359

19. Petersen P, Boysen G, Godtfredsen J, Andersen E, Andersen B (1989) Placebo-controlled, randomised trial of warfarin and aspirin for prevention of thromboembolic complications in chronic atrial fibrillation: the Copenhagen AFASAK study. Lancet 1:175-179

20. Stroke Prevention in Atrial Fibrillation investigators (1991) Stroke prevention in atrial fibrillation study: final results. Circulation 84:527-539

21. The Boston Area Anticoagulation Trial for Atrial Fibrillation investigators (1990) The effect of low-dose warfarin on the risk of stroke in patients with nonrheumatic atrial fibrillation. N Engl J Med 323:1505-1511

22. Connolly SJ, Laupacis A, Gent M, Roberts RS, Cairns JA, Joyner C (1991) Canadian Atrial Fibrillation Anticoagulation (CAFA) study. J Am Coll Cardiol 18:349-355

23. Ezekowitz MD, Bridgers SL, James KE, Carliner NH, Colling CL, Gornick CC, Krause-Steinrauf H, Kurtzke JF, Nazarian SM, Radford MJ (1992) Warfarin in the prevention of stroke associated with nonrheumatic atrial fibrillation. N Engl J Med 327:1406-1412

24. EAFT (European Atrial Fibrillation Trial) study group (1993) Secondary prevention in non-rheumatic atrial fibrillation after transient ischaemic attack or minor stroke. Lancet 342:1255-1262
25. Sherman DG, Kim SG, Boop BS, Corley SD, Dimarco JP, Hart RG, Haywood LJ, Hoyte K, Kaufman ES, Kim MH, Nasco E, Waldo AL; National Heart, Lung, and Blood Institute AFFIRM investigators (2005) Occurrence and characteristics of stroke events in the Atrial Fibrillation Follow-up Investigation of Sinus Rhythm Management (AFFIRM) study. Arch Intern Med 165:1185-1191

26. Dagres N, Nieuwlaat R, Vardas PE (2007) Gender-related differences in presentation, treatment, and outcome of patients with atrial fibrillation in Europe: a report from the Euro Heart survey on atrial fibrillation. J Am Coll Cardiol 49:572-577

27. Poli D, Antonucci E, Grifoni E, Abbate R, Gensini GF, Prisco D (2009) Gender differences in stroke risk of atrial fibrillation patients on oral anticoagulant treatment. Thromb Haemost 101:938-942

28. DiMarco JP, Flaker G, Waldo AL, Corley SD, Greene HL, Safford RE, Rosenfeld LE, Mitrani G, Nemeth M; AFFIRM investigators (2005) Factors affecting bleeding risk during anticoagulant therapy in patients with atrial fibrillation: observations from the Atrial Fibrillation Follow-up Investigation of Rhythm Management (AFFIRM) study. Am Heart J 149: 650-656

29. Humphries KH, Kerr CR, Connolly SJ, Klein G, Boone JA, Green M, Sheldon R, Talajic M, Dorian P, Newman D (2001) New-onset atrial fibrillation: sex differences in presentation, treatment, and outcome. Circulation 103:2365-2370

30. Rose AJ, Hylek EM, Ozonoff A, Ash AS, Reisman JI, Berlowitz DR (2010). Patient characteristics associated with oral anticoagulation control: results of the Veterans Affairs Study to Improve Anticoagulation (VARIA). J Thromb Haemost 8:2182-2191

31. Olsson SB; Executive Steering Committee of the SPORTIF III investigators (2003) Stroke prevention with the oral direct thrombin inhibitor ximelagatran compared with warfarin in patients with non-valvular atrial fibrillation (SPORTIF III): randomised controlled trial. Lancet 362:1691-1698

32. Albers GW, Diener HC, Frison L, Grind M, Nevinson M, Partridge S, Halperin JL, Horrow J, Olsson SB, Petersen P, Vahanian A; SPORTIF Executive Steering Committee for the SPORTIF V investigators (2005) Ximelagatran vs. warfarin for stroke prevention in patients with nonvalvular atrial fibrillation: a randomized trial. J Am Med Assoc 293:690-698

33. Connolly SJ, Ezekowitz MD, Yusuf S, Eikelboom J, Oldgren J, Parekh A, Pogue J, Reilly PA, Themeles E, Varrone J, Wang S, Alings M, Xavier D, Zhu J, Diaz R, Lewis BS, Darius H, Diener HC, Joyner CD, Wallentin L; RE-LY steering committee and investigators (2009) Dabigatran vs. warfarin in patients with atrial fibrillation. N Engl J Med 361: 1139-1151

34. Patel MR, Mahaffey KW, Garg J, Pan G, Singer DE, Hacke W, Breithardt G, Halperin JL, Hankey GJ, Piccini JP, Becker RC, Nessel CC, Paolini JF, Berkowitz SD, Fox KA, Califf RM; the ROCKET AF investigators (2011) Rivaroxaban vs. warfarin in nonvalvular atrial fibrillation. N Engl J Med 365:883-891

35. Granger CB, Alexander JH, McMurray JJ, Lopes RD, Hylek EM, Hanna M, Al-Khalidi HR, Ansell J, Atar D, Avezum A, Bahit MC, Diaz R, Easton JD, Ezekowitz JA, Flaker G, Garcia D, Geraldes M, Gersh BJ, Golitsyn S, Goto S, Hermosillo AG, Hohnloser SH, Horowitz J, Mohan P, Jansky P, Lewis BS, Lopez-Sendon JL, Pais P, Parkhomenko A, Verheugt FW, Zhu J, Wallentin L; ARISTOTLE Committees and investigators (2011) Apixaban vs. warfarin in patients with atrial fibrillation. N Engl J Med 365: 981-992 
36. Eikelboom JW, Wallentin L, Connolly SJ, Ezekowitz M, Healey JS, Oldgren J, Yang S, Alings M, Kaatz S, Hohnloser SH, Diener HC, Franzosi MG, Huber K, Reilly P, Varrone J, Yusuf S (2011) Risk of bleeding with 2 doses of dabigatran compared with warfarin in older and younger patients with atrial fibrillation: an analysis of the randomized evaluation of long-term anticoagulant therapy (RE-LY) trial. Circulation 123:2363-2372

37. Hart RG, Diener HC, Yang S, Connolly SJ, Wallentin L, Reilly PA, Ezekowitz MD, Yusuf S (2012) Intracranial hemorrhage in atrial fibrillation patients during anticoagulation with warfarin or dabigatran: the RE-LY trial. Stroke 43:1511-1517
38. Steffel J, Braunwald E (2011) Novel oral anticoagulants: focus on stroke prevention and treatment of venous thrombo-embolism. Eur Heart J 32:1968-1976, 1976a 